\title{
Differential Effects of Acetylcholinesterase Inhibitors on Clinical Responses and Cerebral Blood Flow Changes in Patients with Alzheimer's Disease: A 12-Month, Randomized, and Open-Label Trial
}

\author{
Soichiro Shimizu Hidekazu Kanetaka Daisuke Hirose Hirohumi Sakurai \\ Haruo Hanyu \\ Department of Geriatric Medicine, Tokyo Medical University, Tokyo, Japan
}

\section{Key Words}

Acetylcholinesterase inhibitors · Donepezil · Rivastigmine $\cdot$ Galantamine $\cdot$ Regional cerebral blood flow · Single-photon emission computed tomography · Alzheimer's disease

\section{Abstract}

Background/Aims: The present study evaluated the differences in treatment outcomes and brain perfusion changes among 3 types of acetylcholinesterase inhibitors (AchEIs, i.e. donepezil, rivastigmine, and galantamine). Methods: This was a prospective, longitudinal, randomized, open-label, 3-arm (donepezil, rivastigmine, or galantamine), parallel-group, 12-month clinical trial carried out in 55 patients with AD. Results: At 6 months, the results of the MiniMental State Examination (MMSE) and the Trail Making Test (TMT)-Part A showed an improvement versus baseline in the donepezil treatment group. All groups showed a significant increase in regional cerebral blood flow (rCBF), mainly in the frontal lobe. Significant rCBF reduction was observed in the temporal lobe and cingulate gyrus in all 3 groups. Conclusion: AchEI treatment prevents the progression of cognitive impairment and increases the relative rCBF in the frontal lobe.

(c) 2015 S. Karger AG, Basel

\section{Introduction}

Currently, there are 4 types of pharmacological treatments for Alzheimer's disease (AD) available in Japan, namely the acetylcholinesterase inhibitors (AchEIs) donepezil, rivastigmine, and galantamine, and the NMDA receptor antagonist memantine. AchEIs are the standard treatment for patients with mild-to-moderate $\mathrm{AD}[1,2]$. 
AchEIs each work via characteristic mechanisms [3-7]. From reports of various metaanalyses on the efficacy of individual AchEIs, it is generally accepted that AChEIs have significant favorable effects on cognition [8-10]. On the other hand, one open-label randomized study reported a statistically significant improvement in behavioral and psychological symptoms of dementia (BPSD) in patients treated with memantine, donepezil, and rivastigmine, but not in those treated with galantamine [11]. Therefore, whether the various AchEIs exert differential effects on AD patients remains largely unknown.

Functional neuroimaging methods, such as positron emission tomography and singlephoton emission computed tomography (SPECT), are widely used in the diagnosis and understanding of the pathophysiology of patients with AD. Past studies have shown changes in the regional cerebral blood flow (rCBF) and regional cerebral glucose metabolism (rCBMglc) of patients with AD receiving AchEI therapy [12-19]. Most studies showed that AchEI therapy in patients with $\mathrm{AD}$ is associated with $\mathrm{rCBF}$ and $\mathrm{rCBMglc}$ changes, mainly in the frontal lobe. However, there was little difference in the effects of each AChEI on rCBF and rCBMglc.

The present study aimed to evaluate the differences in treatment outcomes and rCBF changes among the 3 types of AchEIs. To our knowledge, this is the first study in Japan to evaluate the differences in the effects of 3 types of AchEIs on AD patients.

In an attempt to address the question about the differential effects of AchEIs on $\mathrm{AD}$ patients, a randomized, 3-arm, parallel-group, 12-month clinical trial was designed to evaluate the effects of 3 AchEIs (donepezil, rivastigmine, and galantamine) that are currently available for the symptomatic treatment of AD.

\section{Materials and Methods}

\section{Patients}

Patients were eligible to enter the trial if they met all of the following criteria at baseline. The diagnosis of AD was based on the NINCDS-ADRDA criteria [20]. All patients had MiniMental State Examination (MMSE) scores [21] of 10-24 at baseline and a dementia severity of 1 (mild) or 2 (moderate) based on the Clinical Dementia Rating [22]. Patients were excluded if they had the following: evidence of other neurologic or psychiatric disorders (i.e., stroke, Parkinson's disease, or depression); any medication with central nervous system activity; coexisting severe medical conditions or terminal diseases that would compromise the patient's ability to safely complete the trial, and abnormal results of biochemical analysis that may affect cognition (i.e., vitamin $\mathrm{B}_{12}$ deficiency, hypothyroidism, hyperammonemia, etc.).

None of the patients had the following: concomitant treatment with cholinomimetics, tricyclic antidepressants, or neuroleptics; concomitant treatment with any other psychotropic medication at the time of the first visit and during the study; evidence of bradyarrhythmia in the baseline electrocardiogram, and a history of alcohol abuse. The patients were permitted to continue receiving a fixed dose of other medications classified as antihypertensives, anticoagulants, antiplatelets, diuretics, lipid-reducing agents, and antidiabetic drugs. They underwent neuropsychological battery testing at baseline, and after 6 and 12 months of treatment, and SPECT at baseline and after 12 months of treatment.

\section{Study Design}

This was a prospective, longitudinal, randomized, open-label, 3-arm, parallel-group, 12-month clinical trial comparing donepezil, rivastigmine, and galantamine.

We recruited 75 first-visit outpatients with AD, who fulfilled the conditions described in the Patients section above, from the Memory Disorder Clinic at the Department of Geriatric Medicine, Tokyo Medical University. For treatment-group allocation, we prepared 25 sheets 
of paper (12 sheets for men, 13 sheets for women) with the name of each of the 3 AchEIs and put them in an envelope. The patients were asked to choose one of these envelopes. Patients were hence randomized to receive treatment with 1 of the 3 AchEIs for 12 months. The dosages of all AchEIs in this study were set to those approved for mild-to-moderate AD by the Ministry of Health, Labour and Welfare of Japan. Oral donepezil was administered at a dose of $5 \mathrm{mg}$ per day, transdermal rivastigmine at $18 \mathrm{mg}$ per day, and oral galantamine at $24 \mathrm{mg}$ per day. According to the results of a pivotal clinical trial, donepezil has been judged to be effective for mild-to-moderate $\mathrm{AD}$ at a dosage of $5 \mathrm{mg}$ per day in Japan [23]. We assessed adverse events by medical examination, laboratory tests, and electrocardiogram 30 days after the start of AChEI treatment. Twenty-eight similarly aged healthy control subjects (12 men and 16 women), ranging from 51 to 85 years old (mean age $74.3 \pm 8.5$ years), were also included for the SPECT analysis.

This study was approved by the Ethics Committee of Tokyo Medical University. Informed consent for the SPECT studies was obtained from all control subjects. For the patients, consent was obtained before entry, following a detailed explanation of the study's aim. It was obtained from either the patients themselves or their closest relative. All procedures were in accordance with ethical standards on human investigation and with the principles of the declaration of Helsinki.

\section{Assessment}

Treatment effects were evaluated at baseline, and after 6 and 12 months of treatment using the following 5 multidimensional rating scales: MMSE [21], Alzheimer's Disease Assessment Scale-Cognitive Subscale (ADAS-cog) [24], Trail Making Test (TMT)-Part A [25], Neuropsychiatric Inventory (NPI) [26], and Functional Activities Questionnaire (FAQ) [27]. MMSE and ADAS-cog were regarded as evaluating cognitive function. Furthermore, among the subitems of the ADAS-cog, we regarded items 1, 9, 10, and 11 as measures of memory, items $2,3,4,5$, and 6 as measures of language, and 7 and 8 as measures of praxis. TMT-Part A was regarded as assessment of the frontal lobe function, and NPI and FAQ were regarded as BPSD assessment by the caregiver. Assessments were performed by an experienced clinical psychologist who was blind to the patients' clinical data.

\section{SPECT Imaging}

All subjects were imaged using a triple-head rotating gamma camera (PRISM $3000 \mathrm{XP}$, Picker) with a fan-beam collimator that permits a spatial resolution of 6.8-mm full width at half maximum. Imaging was started 15 min after intravenous injection with $222 \mathrm{MBq}$ of $\mathrm{N}$-isopropyl- $p$ - $\left[{ }^{123} \mathrm{I}\right]$ iodoamphetamine. In practice, full width at half maximum would be higher (approximately 10-12 mm) when scanning subjects because of the increase in source to collimator distances together with the effects of scattering within subjects, both of which degrade spatial resolution. Prior to the injection, the subjects sat in quiet and relaxed surroundings with their eyes open for $10 \mathrm{~min}$. After the injection, the subjects lay down with their eyes closed during the imaging. SPECT images were acquired in 24 steps $(72$ projections), each of which collected counts for $40 \mathrm{~s}$. Reconstruction of the images was performed by filtered back-projection using Butterworth and Ramp filters (order 8; cutoff 0.40/cm) with attenuation correction (Chang method, $0.09 / \mathrm{cm}$ ). The matrix size and slice thickness of the SPECT images were $128 \times 128 \mathrm{~mm}$ and $4.3 \mathrm{~mm}$, respectively.

\section{3-Dimensional Stereotactic Surface Projection Analysis}

A 3-dimensional stereotactic surface projection (3D-SSP) created with the Neurological Statistical Image Analysis Software (NEUROSTAT), developed by Minoshima et al. [28], was used to evaluate the spatial distribution of abnormal CBF. Image analysis was performed on 


\section{Fig. 1. Study design.}

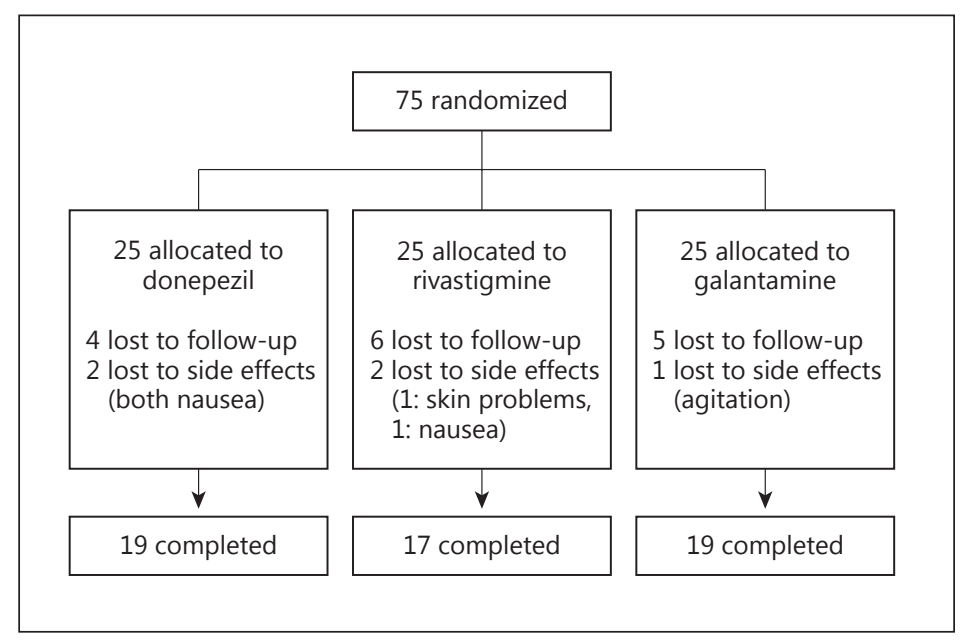

a personal computer equipped with the Windows 2000 operating system, in which the MS-DOS version of NEUROSTAT was implemented. Each image set was realigned to the bicommissure stereotactic coordinate system [29]. Differences in individual brain sizes were adjusted by linear scaling, and regional anatomical differences were minimized by a nonlinear warping technique [30]. As a result, each brain was standardized anatomically to match a standard atlas brain while preserving regional perfusion activity. Subsequently, maximum cortical activity was extracted to adjacent predefined surface pixels on a pixel-by-pixel basis using the 3D-SSP technique [28]. To quantify perfusion changes, the normalized brain activity of each patient was compared with that of 28 normal controls using pixel-by-pixel Z-score analysis (normal mean - individual value/normal SD). Thus, the 3D-SSP technique can transform a SPECT image of a subject to Talairach coordinates (anatomical standardization), and the regions of the 3D-SSP Z-score image correctly correspond to the Talairach coordinates $[28,29]$. A positive Z-score represented an increase in $\mathrm{rCBF}$, and a negative Z-score represented a decrease in $\mathrm{rCBF}$ in the patient relative to the mean of the controls.

\section{Image Analysis}

To demonstrate regional changes in $\mathrm{rCBF}$, differences between the baseline and the endpoint were compared in each group using the paired $t$ test. For this comparison, we used a threshold of changes in Z-score $\geq 1.64$ (corresponding to a p value $\leq 0.05$ ). Moreover, we identified regions of Talairach coordinates with changes in Z-scores $\geq 3$ (corresponding to a p value $<0.005)[28,29]$.

\section{Statistical Analysis}

Values are expressed as means \pm SD. Comparisons among the 3 groups were performed by one-way analysis of variance and changes of multidimensional rating scales in each group were analyzed by the paired t test. A p value $<0.05$ was considered to indicate a statistically significant difference between the 2 groups.

\section{Results}

Seventy-five patients (32 men and 43 women between 72 and 87 years old; mean age $74.3 \pm 4.2$ years) were randomly assigned to receive 1 of the 3 treatments. Figure 1 shows the study design. Twenty-five patients were allocated to each group, namely, the donepezil group 


\begin{tabular}{|c|c|c|c|}
\hline \multicolumn{4}{|c|}{ Dement Geriatr Cogn Disord Extra 2015;5:125-146 } \\
\hline \multicolumn{2}{|c|}{ DOI: 10.1159/000375527 } & \multicolumn{2}{|c|}{$\begin{array}{l}\text { (c) } 2015 \text { S. Karger AG, Basel } \\
\text { www.karger.com/dee }\end{array}$} \\
\hline \multicolumn{4}{|c|}{$\begin{array}{l}\text { Shimizu et al.: Differential Effects of Acetylcholinesterase Inhibitors on Clinical } \\
\text { Responses and Cerebral Blood Flow Changes in Patients with Alzheimer's Disease }\end{array}$} \\
\hline & $\begin{array}{l}\text { Donepezil } \\
(n=25)\end{array}$ & $\begin{array}{l}\text { Rivastigmine } \\
(\mathrm{n}=25)\end{array}$ & $\begin{array}{l}\text { Galantamine } \\
(\mathrm{n}=25)\end{array}$ \\
\hline Nausea & $3(12.0)$ & $2(8.0)$ & $1(4.0)$ \\
\hline Vomiting & $2(8.0)$ & $1(4.0)$ & 0 \\
\hline Headache & $1(4.0)$ & $1(4.0)$ & $1(4.0)$ \\
\hline Dizziness & 0 & $1(4.0)$ & $1(4.0)$ \\
\hline Sedation & 0 & 0 & $2(8.0)$ \\
\hline Skin problems & 0 & $2(8.0)$ & 0 \\
\hline Anorexia & $1(4.0)$ & 0 & 0 \\
\hline Agitation & 0 & 0 & $1(4.0)$ \\
\hline
\end{tabular}

Table 1. Adverse events reported in the 3 groups

Data are presented as number (\%) of patients.

Table 2. Demographic features of the patients

\begin{tabular}{lccc}
\hline & Donepezil $(\mathrm{n}=19)$ & Rivastigmine $(\mathrm{n}=17)$ & Galantamine $(\mathrm{n}=19)$ \\
\hline Age, years & $78.4 \pm 6.5$ & $77.2 \pm 5.4$ & $77.4 \pm 6.0$ \\
Gender, men/women & $9 / 10$ & $8 / 11$ & $8 / 9$ \\
Length of education, years & $12.3 \pm 2.4$ & $13.2 \pm 3.0$ & $11.0 \pm 2.5$ \\
Duration of disease, years & $3.1 \pm 0.8$ & $2.6 \pm 0.9$ & $3.2 \pm 0.8$ \\
APOE $\varepsilon 4$ carrier, $\mathrm{n}(\%)$ & $10(52.6)$ & $9(52.9)$ & $9(47.4)$ \\
Duration of medication, months & $12.3 \pm 2.4$ & $12.8 \pm 1.8$ & $11.8 \pm 2.2$ \\
\hline
\end{tabular}

$\mathrm{APOE}=$ Apolipoprotein E

(mean dosage: $5 \mathrm{mg}$ per day), the rivastigmine group (mean dosage: $18 \mathrm{mg}$ per day), and the galantamine group (mean dosage: $24 \mathrm{mg}$ per day). All patients received at least 1 dose of the assigned treatment and had at least 1 valid postbaseline assessment using the neuropsychological battery. In total, 55 patients (73.3\%) completed the study according to the protocol. A total of 20 patients $(26.7 \%)$ withdrew from the study, of whom $5(6.6 \%)$ discontinued treatment owing to side effects as shown in figure 1 . There was no significant difference in the frequency of side effects among the 3 groups. Adverse events were reported in $28.0 \%$ of the patients $(7 / 25)$ in the donepezil group, in $28.0 \%(7 / 25)$ of the patients in the rivastigmine group, and in $24.0 \%(6 / 25)$ of the patients in the galantamine group. Table 1 shows the adverse events reported in the 3 groups. Nausea and vomiting were the most common adverse events, followed by headache and dizziness. Most adverse events in all the groups were transient, of mild-to-moderate severity, and resolved spontaneously with no need for intervention. There were no clinically significant changes from baseline in the clinical laboratory parameters and in the vital signs of all 3 groups.

Table 2 shows the demographic features of the patients. No significant differences in the 3 groups were found in terms of age, sex, length of education, duration of disease, and duration of treatment.

Table 3 shows the results of the 5 multidimensional rating scales in the 3 treatment groups. No significant differences in the 3 groups were observed in the 5 multidimensional rating scale scores at baseline, and after 6 and 12 months. After 6 months of treatment, the results of MMSE and TMT-Part A showed an improvement versus baseline in the donepezil treatment group (MMSE: $\mathrm{p}<0.01$; TMT-Part A: $\mathrm{p}<0.05$ ). At 12 months after treatment, no significant changes were observed except that the FAQ score in the galantamine group was 
Table 3. Results of the 5 multidimensional rating scales in the 3 treatment groups

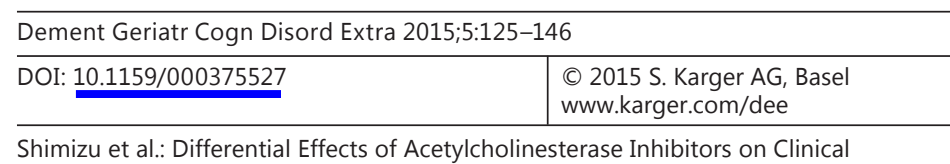

Shimizu et al.: Differential Effects of Acetylcholinesterase Inhibitors on Clinical

Responses and Cerebral Blood Flow Changes in Patients with Alzheimer's Disease

\begin{tabular}{lrrr}
\hline & Baseline & 6 months & 12 months \\
\hline MMSE & & & \\
$\quad$ Donepezil & $21.0 \pm 3.9$ & $22.0 \pm 3.3^{*}$ & $21.3 \pm 4.3$ \\
$\quad$ Rivastigmine & $21.0 \pm 3.5$ & $22.6 \pm 3.2$ & $21.1 \pm 3.6$ \\
$\quad$ Galantamine & $20.8 \pm 3.7$ & $21.6 \pm 3.3$ & $18.9 \pm 3.7$ \\
ADAS-cog & & & \\
$\quad$ Donepezil & $18.2 \pm 8.1$ & $16.6 \pm 5.9$ & $16.5 \pm 8.0$ \\
$\quad$ Rivastigmine & $16.9 \pm 4.6$ & $17.2 \pm 3.8$ & $16.5 \pm 4.1$ \\
$\quad$ Galantamine & $15.5 \pm 5.4$ & $16.6 \pm 6.9$ & $18.6 \pm 7.2$ \\
TMT-Part A & & & \\
$\quad$ Donepezil & $107.5 \pm 35.9$ & $86.5 \pm 34.4^{\#}$ & $89.9 \pm 36.8$ \\
$\quad$ Rivastigmine & $95.3 \pm 33.5$ & $98.2 \pm 35.2$ & $80.7 \pm 28.7$ \\
$\quad$ Galantamine & $88.8 \pm 37.5$ & $100.3 \pm 42.1$ & $85.6 \pm 48.3$ \\
NPI & & & \\
$\quad$ Donepezil & $4.2 \pm 2.8$ & $3.9 \pm 2.7$ & $3.5 \pm 3.0$ \\
$\quad$ Rivastigmine & $4.3 \pm 4.5$ & $3.6 \pm 2.8$ & $4.0 \pm 3.9$ \\
$\quad$ Galantamine & $4.8 \pm 3.1$ & $3.7 \pm 2.2$ & $4.8 \pm 3.6$ \\
FAQ & & & \\
Donepezil & $13.4 \pm 8.1$ & $14.4 \pm 6.3$ & $12.6 \pm 7.3$ \\
$\quad$ Rivastigmine & $12.9 \pm 6.2$ & $13.6 \pm 4.5$ & $13.4 \pm 4.2$ \\
Galantamine & $12.3 \pm 6.7$ & $13.4 \pm 6.3$ & $15.9 \pm 7.6^{\dagger}$ \\
\hline
\end{tabular}

${ }^{\#} \mathrm{p}<0.05,{ }^{*} \mathrm{p}<0.01$, improvement versus baseline; ${ }^{\dagger} \mathrm{p}<0.01$ worsening versus baseline.

significantly worse compared with that at the baseline $(\mathrm{p}<0.01)$. Figure 2 shows the changes in the 5 multidimensional rating scale scores.

Tables 4 and 5 show the results of each assessment category of ADAS-cog (described above) and of the individual domains of the NPI in the 3 treatment groups. Regarding the assessment categories of ADAS-cog, praxis was significantly improved in the rivastigmine group at 12 months $(\mathrm{p}<0.01)$ (table 3$)$. The analysis of the results in the individual domains of the NPI showed that at 12 months, agitation/aggression was significantly worse in the galantamine group ( $p<0.01$ ), whereas aberrant motor behavior was significantly improved in the galantamine group $(\mathrm{p}<0.05)$ (table 5$)$.

Figure 3 shows the 3 -dimensional images of significant $\mathrm{rCBF}$ changes from baseline at the endpoint in each of the groups. The red scale indicates relative increases in $\mathrm{rCBF}$ and the blue scale indicates relative decreases in $\mathrm{rCBF}$. All groups showed a significant increase in $\mathrm{rCBF}$ in the frontal lobe. Specifically, the donepezil group showed an rCBF increase in the frontal pole and orbital surface. The rivastigmine group showed an rCBF increase in the lateral and medial frontal lobe as well as the cingulate and occipital lobe. The galantamine group showed an rCBF increase in the frontal lobe and the occipital lobe. Particularly, the 3-dimensional images showed that the rivastigmine and galantamine groups had an extensive and intense rCBF increase in the frontal lobe and the occipital lobe. Significant decreases in rCBF in the 3 groups were observed in the temporal lobe and the cingulate gyrus. In particular, there was a tendency for significant $\mathrm{rCBF}$ reduction in the medial temporal lobe in the donepezil group and in the cingulate in the galantamine group. Regarding the cerebellum, a similar increase or decrease in $\mathrm{rCBF}$ was observed in all groups.

Table 6 shows the regions of relative perfusion changes in the 3 treatment groups (Z-score changes $\geq 3$ ). 


\begin{tabular}{|c|c|c|c|c|c|c|}
\hline \multirow[t]{2}{*}{$\begin{array}{l}\text { Dementia } \\
\text { and Geriatric } \\
\text { Cognitive Disorders }\end{array}$} & \multicolumn{4}{|c|}{ DOI: $10.1159 / 000375527$} & \multicolumn{2}{|c|}{$\begin{array}{l}\text { (c) } 2015 \text { S. Karger AG, Basel } \\
\text { www.karger.com/dee }\end{array}$} \\
\hline & \multicolumn{6}{|c|}{$\begin{array}{l}\text { Shimizu et al.: Differential Effects of Acetylcholinesterase Inhibitors on Clinical } \\
\text { Responses and Cerebral Blood Flow Changes in Patients with Alzheimer's Disease }\end{array}$} \\
\hline \multirow[t]{2}{*}{ ADAS-cog category } & \multicolumn{2}{|l|}{ Donepezil } & \multicolumn{2}{|c|}{ Rivastigmine } & \multicolumn{2}{|c|}{ Galantamine } \\
\hline & 6 months & 12 months & 6 months & 12 months & 6 months & 12 months \\
\hline Memory: $1+9+10$ + 11 & $-4.8 \pm 7.7$ & $-7.1 \pm 8.5$ & $-2.1 \pm 5.3$ & $-3.9 \pm 6.2$ & $-1.1 \pm 7.1$ & $-3.5 \pm 7.6$ \\
\hline Language: $2+3+4+5+6$ & $-0.7 \pm 1.5$ & $-0.6 \pm 1.3$ & $-0.0 \pm 0.8$ & $-0.1 \pm 0.9$ & $0.1 \pm 1.2$ & $0.1 \pm 1.2$ \\
\hline Praxis: $7+8$ & $-0.4 \pm 2.2$ & $-0.9 \pm 2.4$ & $-0.6 \pm 1.5$ & $-1.6 \pm 1.6^{*}$ & $-0.8 \pm 2.2$ & $-1.2 \pm 2.1$ \\
\hline
\end{tabular}

Table 4. Effects of AchEIs on ADAS-cog scores for each assessment category

Values are expressed as changes from baseline (means \pm SD). ${ }^{*} \mathrm{p}<0.01$, improvement versus baseline.

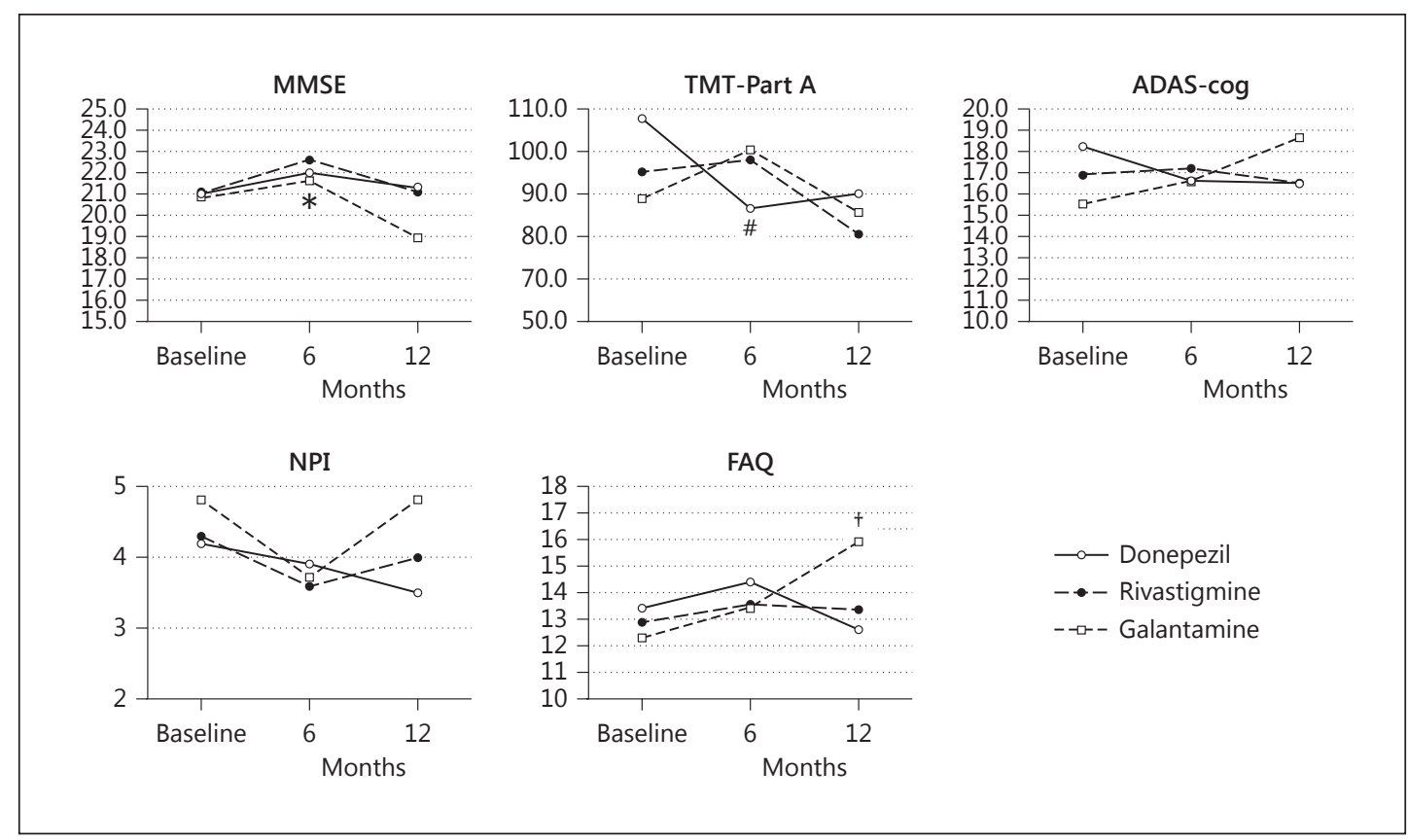

Fig. 2. Effect of AchEIs on $\mathrm{AD}$ patients in the 3 subgroups analyzed by 5 multidimensional rating scales. ${ }^{\#} \mathrm{p}<0.05{ }^{*} \mathrm{p}<0.01$, improvement versus baseline in the donepezil group; ${ }^{\dagger} \mathrm{p}<0.01$, worsening versus baseline in the galantamine group.

Fig. 3. Statistical maps showing perfusion changes in the 3 treatment groups. Increased perfusion is indicated by 'hot' colors and decreased perfusion by 'cold' colors. All treatment groups showed a significant increase in rCBF mainly in the frontal lobe. A significant reduction in $\mathrm{rCBF}$ was observed in the temporal lobe and cingulate gyrus of all treatment groups.

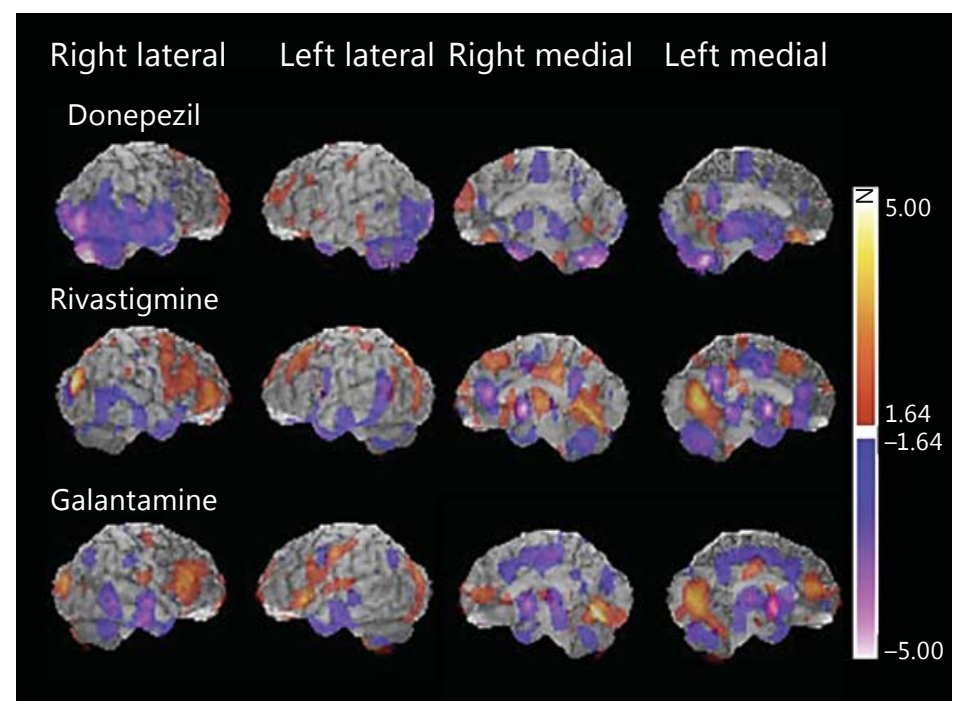


Table 5. Effects of AchEIs on NPI subdomains

\begin{tabular}{|c|c|c|c|c|c|c|}
\hline \multirow[t]{2}{*}{ NPI subdomain } & \multicolumn{2}{|c|}{ Donepezil } & \multicolumn{2}{|c|}{ Rivastigmine } & \multicolumn{2}{|c|}{ Galantamine } \\
\hline & 6 months & 12 months & 6 months & 12 months & 6 months & 12 months \\
\hline Delusions & $-0.2 \pm 0.4$ & $-0.1 \pm 0.7$ & $-0.4 \pm 0.9$ & $-0.2 \pm 1.2$ & $-0.1 \pm 0.5$ & $0.0 \pm 0.5$ \\
\hline Hallucinations & $0.1 \pm 0.2$ & $0.0 \pm 0.0$ & $0.0 \pm 0.4$ & $0.1 \pm 0.8$ & $-0.1 \pm 0.3$ & $-0.1 \pm 0.3$ \\
\hline Agitation/aggression & $0.1 \pm 0.8$ & $0.0 \pm 1.0$ & $-0.4 \pm 1.1$ & $-0.3 \pm 0.9$ & $0.2 \pm 0.8$ & $0.8 \pm 0.8^{*}$ \\
\hline Depression/dysphoria & $0.0 \pm 0.8$ & $0.0 \pm 0.7$ & $-0.1 \pm 0.5$ & $0.1 \pm 0.6$ & $0.1 \pm 0.8$ & $0.2 \pm 0.6$ \\
\hline Anxiety & $-0.2 \pm 0.7$ & $-0.1 \pm 0.9$ & $0.0 \pm 1.0$ & $-0.1 \pm 0.8$ & $-0.1 \pm 0.5$ & $0.1 \pm 0.7$ \\
\hline Euphoria & $0.1 \pm 0.3$ & $0.1 \pm 0.3$ & $-0.2 \pm 0.6$ & $-0.2 \pm 0.6$ & $0.0 \pm 0.4$ & $0.1 \pm 0.3$ \\
\hline Apathy & $-0.3 \pm 1.0$ & $0.1 \pm 1.1$ & $0.1 \pm 1.2$ & $0.2 \pm 0.8$ & $-0.2 \pm 0.8$ & $-0.3 \pm 0.7$ \\
\hline Disinhibition & $0.1 \pm 0.4$ & $0.0 \pm 0.4$ & $-0.1 \pm 0.6$ & $-0.2 \pm 0.6$ & $0.4 \pm 0.5$ & $0.0 \pm 0.0$ \\
\hline Irritability/lability & $0.1 \pm 1.0$ & $-0.1 \pm 1.1$ & $-0.1 \pm 0.8$ & $0.1 \pm 0.9$ & $0.1 \pm 0.7$ & $0.4 \pm 0.7$ \\
\hline Aberrant motor behavior & $-0.2 \pm 0.7$ & $-0.4 \pm 0.8$ & $-0.2 \pm 0.6$ & $-0.1 \pm 0.9$ & $-0.3 \pm 0.5$ & $-0.4 \pm 0.5^{\#}$ \\
\hline Sleep disturbance & $0.0 \pm 0.7$ & $0.1 \pm 0.7$ & $-0.1 \pm 1.0$ & $-0.1 \pm 0.8$ & $0.0 \pm 0.4$ & $0.4 \pm 0.7$ \\
\hline Appetite and eating disturbance & $-0.1 \pm 0.4$ & $-0.1 \pm 0.4$ & $0.1 \pm 0.7$ & $0.3 \pm 0.8$ & $-0.1 \pm 0.7$ & $0.0 \pm 0.8$ \\
\hline
\end{tabular}

Values are expressed as changes from baseline (means $\pm \mathrm{SD}$ ). ${ }^{\#} \mathrm{p}<0.05,{ }^{*} \mathrm{p}<0.01$, worsening versus baseline.

Table 6. Brain regions showing relative perfusion changes in the 3 treatment groups

\begin{tabular}{|c|c|c|c|c|c|c|}
\hline & \multicolumn{2}{|c|}{ Donepezil } & \multicolumn{2}{|c|}{ Rivastigmine } & \multicolumn{2}{|c|}{ Galantamine } \\
\hline & $\begin{array}{l}\text { Z- } \\
\text { score }\end{array}$ & region & $\begin{array}{l}\text { Z- } \\
\text { score }\end{array}$ & region & $\begin{array}{l}\text { Z- } \\
\text { score }\end{array}$ & region \\
\hline \multicolumn{7}{|c|}{ rCBF increase } \\
\hline \multirow[t]{8}{*}{ Left } & 4.41 & Medial frontal gyrus, GM (BA 11) & 4.36 & Cuneus & 4.01 & Superior temporal gyrus, GM (BA 13) \\
\hline & 4.22 & Precuneus, GM (BA 31) & 3.75 & Precuneus, WM & 3.53 & Lateral globus pallidus \\
\hline & 4.15 & Middle temporal gyrus, WM & 3.35 & Middle frontal gyrus, GM (BA 8) & 3.37 & Precentral gyrus, GM (BA 4) \\
\hline & 3.89 & Insula, WM & & & & \\
\hline & 3.33 & Middle frontal gyrus, GM (BA 9) & & & & \\
\hline & 3.20 & Middle frontal gyrus, WM & & & & \\
\hline & 3.10 & Postcentral gyrus, WM & & & & \\
\hline & 3.02 & Middle frontal gyrus, GM (BA 10) & & & & \\
\hline \multirow[t]{5}{*}{ Right } & 4.05 & Putamen & 5.19 & Middle occipital gyrus, GM (BA 19) & 3.74 & Middle occipital gyrus, GM (BA 19) \\
\hline & 3.84 & Superior frontal gyrus, WM & 3.66 & Lingual gyrus, $\mathrm{WM}$ & 3.37 & Lentiform nucleus \\
\hline & 3.20 & Superior frontal gyrus, GM (BA 10) & 3.39 & Precuneus ,GM (BA 7) & & \\
\hline & 3.20 & Superior frontal gyrus, WM & 3.32 & Thalamus (medial dorsal nucleus) & & \\
\hline & & & 3.24 & Thalamus & & \\
\hline \multicolumn{7}{|c|}{ rCBF decrease } \\
\hline \multirow[t]{8}{*}{ Left } & -3.01 & Superior temporal gyrus, WM & -3.00 & Cingulate gyrus, GM (BA 24) & -3.08 & Sublobar, extranuclear, WM \\
\hline & -3.05 & Cuneus, WM & -3.34 & Inferior semilunar lobule, GM & -3.10 & Subgyral, WM \\
\hline & -4.59 & Sublobar, extranuclear, WM & -3.64 & Middle temporal gyrus, GM (BA 21) & -3.18 & Inferior parietal lobule, WM \\
\hline & -5.43 & Sublobar, extranuclear, WM & -3.76 & Medial frontal gyrus, GM (BA 10) & -3.26 & Caudate head \\
\hline & & & -3.98 & Subgyral, WM & -3.38 & Caudate tail \\
\hline & & & -4.02 & Cingulate gyrus, GM (BA 31) & & \\
\hline & & & -4.06 & Superior temporal gyrus, GM (BA 38) & & \\
\hline & & & -4.45 & Subgyral & & \\
\hline \multirow[t]{6}{*}{ Right } & -3.01 & Thalamus (medial dorsal nucleus) & -3.00 & Subgyral, WM & -3.18 & Middle temporal gyrus, WM \\
\hline & -3.38 & Supramarginal gyrus, WM & -3.50 & Inferior temporal gyrus, GM (BA 20) & -3.82 & Anterior cingulate \\
\hline & -3.56 & Middle temporal gyrus, GM (BA 21) & -4.00 & Temporal lobe & -3.87 & Cingulate gyrus, WM \\
\hline & -3.86 & Superior temporal gyrus, WM & -4.31 & Anterior cingulate, GM (BA 32) & & \\
\hline & -4.02 & Medial frontal gyrus, GM (BA 6) & -4.73 & Sublobar, extranuclear, WM & & \\
\hline & -4.80 & Uncus, GM (BA 28) & & & & \\
\hline
\end{tabular}

Regions with Z-score changes $\geq 3$ are shown. GM = Gray matter; $\mathrm{WM}=$ white matter; $\mathrm{BA}=$ approximate Brodmann area. 


\section{Discussion}

The most important purpose of treatment in $\mathrm{AD}$ patients is to improve (or maintain) the cognitive level and BPSD. Thus, AchEIs are effective therapies for these symptoms.

The AchEIs work via various characteristic mechanisms. Donepezil is a strong AchEI with a strong inhibitory effect that is about 122 times higher against butyrylcholinesterase (BuChE) than against AchE [3]. On the other hand, rivastigmine is thought to act via inhibition of both AchE and BuChE [4]. Galantamine is an AchEI that is thought to modulate multiple subtypes of nicotinic acetylcholine receptors [7].

To our knowledge, this is the first prospective open-label long-term study that evaluated treatment outcomes and rCBF changes of all 3 types of AchEIs at the same time. We found 2 main results in this study. First, all AchEIs prevented the progression of cognitive impairment after 12 months of treatment, as shown by no significant decreases compared with baseline in MMSE and ADAS-cog total scores. Second, a greater relative rCBF increase in the frontal lobe was found in all AchEI treatment groups of AD patients.

From the results of previous meta-analysis studies [8-10], it is generally accepted that AChEIs have significant effects on cognition. The results of our study showing that progression of cognitive impairment is prevented after 12 months of treatment with any of the AchEIs are consistent with these previous studies. In one previous study, an adjusted indirect comparison showed that both donepezil and rivastigmine performed significantly better than galantamine in global cognitive assessment [8]. This was consistent with our results, showing statistically significant improvements in MMSE and TMT-Part A scores after 6 months of donepezil treatment and a statistically significant improvement in praxis evaluated by ADAS-cog after 12 months of rivastigmine therapy.

The results of individual direct comparison studies [31-34] have been highly variable. In 2 studies comparing donepezil and galantamine, one found no significant differences in their efficacy [31], whereas the other one found significantly better outcomes for donepezil [32]. On the other hand, in the 2 studies comparing donepezil and rivastigmine [33,34], both found the drugs to be similar with regard to cognitive outcomes, whereas the double-blinded study reported small but statistically significant differences in function favoring rivastigmine compared with donepezil [34]. Differences in the results of these studies and our study may be due to differences in the duration of the individual studies (our study: 48 weeks; Wilcock et al. [31]: 52 weeks; Jones et al. [32]: 12 weeks; Wilkinson et al. [33]: 12 weeks, and Bullock et al. [34]: 96 weeks).

Regarding BPSD, Hansen et al. [8] showed that donepezil treatment resulted in significantly improved behaviors in AD patients compared to galantamine treatment in an adjusted indirect comparison study. One randomized, open-label study comparing the effect of 3 AchEIs and memantine on BPSD showed that the improvement in BPSD is statistically significant in all groups except the galantamine group [11]. The results of these studies were consistent with our results showing that galantamine treatment resulted in a significantly worse FAQ score $(\mathrm{p}<0.05)$ and agitation/aggression of NPI $(\mathrm{p}<0.01)$ at 12 months. In contrast, past studies hypothesized that allosteric potentiation at nicotinic receptors by galantamine, which enhances the release of noradrenaline, may result in improvements in BPSD $[35,36]$. However, our results suggest that not only noradrenergic fibers but also various other factors (e.g. premorbid character) may influence changes in character including agitation.

The results of past SPECT and positron emission tomography studies, showing that treatment with AchEIs can improve $\mathrm{CCBF}$ and $\mathrm{rCBMglc}$ in areas of the brain associated with attention as well as mainly the frontal lobe [12-19], are consistent with the results of this study. This result suggested that the frontal cortex might be easily affected by AchEIs, because 
the cholinergic axon to this region was relatively short. Regarding an rCBF decrease, all groups showed a decrease mainly in the temporal lobe and cingulate. In our study, there was little difference in the effect of individual AchEIs on rCBF changes.

The 3D-SSP results showed a small increase in $\mathrm{rCBF}$ in the donepezil group. However, the area of the brain showing a significant $\mathrm{rCBF}$ increase (Z-score changes $\geq 3$ ), which was mainly in the frontal lobe, was relatively large. Thus, this might be caused by the strong effect of donepezil resulting in AchE inhibition. Therefore, donepezil may increase rCBF mainly in the frontal lobe. Moreover, the 3D-SSP results showed a large rCBF decrease in the donepezil group. However, cognitive improvement was found after 6 months of treatment in the donepezil group. We hypothesized 2 possibilities regarding this discrepancy. First, donepezil has a strong inhibitory effect on AchE. Therefore, cognitive improvement was observed regardless of rCBF decreases in regions of the frontal lobe. Second, rCBF was assessed after 12 months of treatment although cognitive improvement was found after 6 months of treatment. On the other hand, an increase in $\mathrm{rCBF}$ was found in the thalamus in the rivastigmine group. Rivastigmine is a dual inhibitor of AchE and BuchE. Both AchE and BuchE can regulate the activity of acetylcholine in the human brain [5, 6]. Many of the thalamic nuclei that are affected in several diseases of the nervous system have a substantial number of neurons that express BuchE [37].

Because galantamine is a relatively weak AchEI but has additional allosteric potentiating effects at the nicotinic receptor, it affects not only cholinergic transmission but also other neurotransmitter systems. Moreover, modulation of neurotransmitter release induced by galantamine was found not only in the frontal lobe but also in regions throughout the whole brain [38]. This allosteric potentiation contributes to neuronal protection against several neurotoxic stimuli [7]. This mechanism of galantamine can explain the results of our study. The result that the galantamine group showed no significant improvement in cognition can be explained by the fact that galantamine is a weak AchEI. The results that increases in rCBF were found in several regions other than the frontal lobe can be explained by the fact that galantamine affects neurotransmitters other than acetylcholine throughout the brain. Moreover, there is a tendency of a small rCBF decrease in the galantamine group. Considering these results, we hypothesized that galantamine may have neuroprotective effects in addition to AchE inhibition.

The results of adverse events in our study were consistent with those of previous clinical trials and meta-analyses [7]. The most common adverse event of patients was nausea (8\%). No important changes in laboratory test values or vital signs were observed.

This study has several critical limitations. First, it was carried out in a single memory disorder clinic; therefore, the number of patients enrolled in each treatment group was relatively small. However, this was a prospective, longitudinal, randomized study of patients. Moreover, it is apparently the first study to evaluate the differences in the effects of treatment with 3 types of AchEIs on rCBF changes. Therefore, although the number of patients was small, we believe that our study is of significance. Furthermore, although assessments were made in a blind manner from the clinical data, this study was conducted according to an openlabel design. Therefore, potential biases in treatment allocation cannot be excluded. In addition, this study did not include an untreated control group that would have allowed us to better quantify the extent of the improvements observed with the treatments under study. Therefore, we could not compare the effects of cognition and rCBF changes in each treatment group with an untreated control group. Finally, a potential weakness is the reliance on clinical rather than neuropathological diagnoses. We rigorously applied standardized sets of diagnostic criteria, all of which have a diagnostic accuracy of above $80 \%$ when judged according to the postmortem diagnosis. Further studies with a larger number of patients and with consideration of the results of pathologic examination are required to confirm our results. 
Nevertheless, the limitations inherent in this community-based study do not marginalize the importance of the information collected from the patients. This type of study is important because it enables us to obtain data in a clinical setting without experimental intervention.

In conclusion, consistent with the results of previous studies, this study found that longterm AchEI treatment prevents the progression of cognitive impairment in patients with AD. A greater relative rCBF increase in the frontal lobe was found in all AchEI treatment groups. Moreover, the results of the neuropsychiatric battery and SPECT study suggest that there is little difference between the effects of each AchEI. Therefore, these results suggest the possibility of selectively using individual AchEIs according to the characteristics of the AD patients.

\section{Acknowledgements}

This study was financially supported by research funding in part by Eisai Co., Ltd., Novartis Pharma K.K., Takeda Chemicalk Industries, Ltd., Janssen Pharmaceutical K.K., and Daiichi-Sankyo Co., Ltd.

\section{References}

1 National Institute for the Health and Clinical Excellence NICE: Donepezil, galantamine, rivastigmine and memantine for the treatment of Alzheimer's disease. 2011.

2 Japanese Society of Neurology: Guideline for dementia disease treatment (in Japanese). 2010.

- 3 Darvesh S, Walsh R, Kumar R, Caines A, Roberts S, Magee D, Rockwood K, Martin E: Inhibition of human cholinesterases by drugs used to treat Alzheimer disease. Alzheimer Dis Assoc Disord 2003;17:117-126.

4 Sim A: Rivastigmine: a review. Hosp Med 1999;60:731-735.

5 Mesulam M, Guillozet A, Shaw P, Quinn B: Widely spread butyrylcholinesterase can hydrolyze acetylcholine in the normal and Alzheimer brain. Neurobiol Dis 2002;9:88-93.

6 Mesulam MM, Guillozet A, Shaw P, Levey A, Duysen EG, Lockridge O: Acetylcholinesterase knockouts establish central cholinergic pathways and can use butyrylcholinesterase to hydrolyze acetylcholine. Neuroscience 2002;110:627-639.

7 Samochocki M, Höffle A, Fehrenbacher A, Jostock R, Ludwig J, Christner C, Radina M, Zerlin M, Ullmer C, Pereira EF, Lübbert H, Albuquerque EX, Maelicke A: Galantamine is an allosterically potentiating ligand of neuronal nicotinic but not of muscarinic acetylcholine receptors. J Pharmacol Exp Ther 2003;305:1024-1036.

8 Hansen RA, Gartlehner G, Webb AP, Morgan LC, Moore CG, Jonas DE: Efficacy and safety of donepezil, galantamine, and rivastigmine for the treatment of Alzheimer's disease: a systematic review and meta-analysis. Clin Interv Aging 2008;3:211-225.

-9 Campbell N, Ayub A, Boustani MA, Fox C, Farlow M, Maidment I, Howards R: Impact of cholinesterase inhibitors on behavioral and psychological symptoms of Alzheimer's disease: a meta-analysis. Clin Interv Aging 2008;3:719-728.

10 Di Santo SG, Prinelli F, Adorni F, Caltagirone C, Musicco M: A meta-analysis of the efficacy of donepezil, rivastigmine, galantamine, and memantine in relation to severity of Alzheimer's disease. J Alzheimers Dis 2013;35:349-361.

11 Cumbo E, Ligori LD: Differential effects of current specific treatments on behavioral and psychological symptoms in patients with Alzheimer's disease: a 12-month, randomized, open-label trial. J Alzheimers Dis 2014;39:477-485.

12 Tune L, Tiseo PJ, Ieni J, Perdomo C, Pratt RD, Votaw JR, Jewart RD, Hoffman JM: Donepezil HCl (E2020) maintains functional brain activity in patients with Alzheimer disease: results of a 24-week, double-blind, placebocontrolled study. Am J Geriatr Psychiatry 2003;11:169-177.

13 Nakano S, Asada T, Matsuda H, Uno M, Takasaki M: Donepezil hydrochloride preserves regional cerebral blood flow in patients with Alzheimer's disease. J Nucl Med 2001;42:1441-1445.

14 Nobili F, Vitali P, Canfora M, Girtler N, De Leo C, Mariani G, Pupi A, Rodriguez G: Effects of long-term donepezil therapy on rCBF of Alzheimer's patients. Clin Neurophysiol 2002;113:1241-1248.

15 Shimizu S, Hanyu H, Iwamoto T, Koizumi K, Abe K: SPECT follow-up study of cerebral blood flow changes during donepezil therapy in patients with Alzheimer's disease. J Neuroimaging 2006;16:16-23.

16 Cerci SS, Tamam Y, Kaya H, Yildiz M, Arslan S: Effect of rivastigmine on regional cerebral blood flow in Alzheimer's disease. Adv Ther 2007;24:611-621.

-17 Stefanova E, Wall A, Almkvist O, Nilsson A, Forsberg A, Långström B, Nordberg A: Longitudinal PET evaluation of cerebral glucose metabolism in rivastigmine treated patients with mild Alzheimer's disease. J Neural Transm 2006;113:205-218. 
$\$ 18$ Venneri A, Shanks MF, Staff RT, Pestell SJ, Forbes KE, Gemmell HG, Murray AD: Cerebral blood flow and cognitive responses to rivastigmine treatment in Alzheimer's disease. Neuroreport 2002;13:83-87.

19 Keller C, Kadir A, Forsberg A, Porras O, Nordberg A: Long-term effects of galantamine treatment on brain functional activities as measured by PET in Alzheimer's disease patients. J Alzheimers Dis 2011;24:109-123.

-20 McKhann G, Drachman D, Folstein M, Katzman R, Price D, Stadlan EM: Clinical diagnosis of Alzheimer's disease: report of the NINCDS-ADRDA work group under the auspices of department of health and human services task force on Alzheimer's disease. Neurology 1984;34:939-944.

21 Folstein MF, Folstein SE, McHugh PR: 'Mini-Mental State'. A practical method for grading the cognitive state of patients for the clinician. J Psychiatr Res 1975;12:189-198.

22 Hughes CP, Berg L, Danziger WL, Coben LA, Martin RL: A new clinical scale for the staging of dementia. Br J Psychiatry 1982;140:566-572.

23 Homma A, Takeda M, Imai Y, Udaka F, Hasegawa K, Kameyama M, Nishimura T: Clinical efficacy and safety of donepezil on cognitive and global function in patients with Alzheimer's disease. A 24-week, multicenter, double-blind, placebo-controlled study in Japan. E2020 study group. Dement Geriatr Cogn Disord 2000;11: 299-313.

24 Rosen WG, Mohs RC, Davis KL: A new rating scale for Alzheimer's disease. Am J Psychiatry 1984;141:13561364.

25 Army Individual Test Battery. Manual of Directions and Scoring. Washington, War Depratment, Adjutant General's Office, 1944.

26 Cummings JL, Mega M, Gray K, Rosenberg-Thompson S, Carusi DA, Gornbein J: The neuropsychiatric inventory: comprehensive assessment of psychopathology in dementia. Neurology 1994;44:2308-2314.

27 Pfeffer RI, Kurosaki TT, Harrah CH, Chance JM, Filos S: Measurement of functional activities in older adults in the community. J Gerontol 1982;37:323-329.

-28 Minoshima S, Frey KA, Koeppe RA, Foster NL, Kuhl DE: A diagnostic approach in Alzheimer's disease using three-dimensional stereotactic surface projections of fluorine-18-FDG PET. J Nucl Med 1995;36:1238-1248.

29 Talairach J, Tournoux P: Co-Planar Stereotactic Atlas of the Human Brain. New York, Thieme, 1998.

30 Minoshima S, Koeppe RA, Frey KA, Kuhl DE: Anatomic standardization: linear scaling and nonlinear warping of functional brain images. J Nucl Med 1994;35:1528-1537.

-31 Wilcock G, Howe I, Coles H, Lilienfeld S, Truyen L, Zhu Y, Bullock R, Kershaw P, Group G-G-S: A long-term comparison of galantamine and donepezil in the treatment of Alzheimer's disease. Drugs Aging 2003;20: 777-789.

-32 Jones RW, Soininen H, Hager K, Aarsland D, Passmore P, Murthy A, Zhang R, Bahra R: A multinational, randomised, 12-week study comparing the effects of donepezil and galantamine in patients with mild to moderate Alzheimer's disease. Int J Geriatr Psychiatry 2004;19:58-67.

-33 Wilkinson DG, Passmore AP, Bullock R, Hopker SW, Smith R, Potocnik FC, Maud CM, Engelbrecht I, Hock C, Ieni JR, Bahra RS: A multinational, randomised, 12-week, comparative study of donepezil and rivastigmine in patients with mild to moderate Alzheimer's disease. Int J Clin Pract 2002;56:441-446.

34 Bullock R, Touchon J, Bergman H, Gambina G, He Y, Rapatz G, Nagel J, Lane R: Rivastigmine and donepezil treatment in moderate to moderately-severe Alzheimer's disease over a 2-year period. Curr Med Res Opin 2005;21:1317-1327.

-35 Kano O, Ito H, Takazawa T, Kawase Y, Murata K, Iwamoto K, Nagaoka T, Hirayama T, Miura K, Nagata R, Kiyozuka T, Aoyagi J, Sato R, Eguchi T, Ikeda K, Iwasaki Y: Clinically meaningful treatment responses after switching to galantamine and with addition of memantine in patients with Alzheimer's disease receiving donepezil. Neuropsychiatr Dis Treat 2013;9:259-265.

-36 Sasaki S, Horie Y: The effects of an uninterrupted switch from donepezil to galantamine without dose titration on behavioral and psychological symptoms of dementia in Alzheimer's disease. Dement Geriatr Cogn Disord Extra 2014;4:131-139.

-37 Darvesh S, Hopkins DA: Differential distribution of butyrylcholinesterase and acetylcholinesterase in the human thalamus. J Comp Neurol 2003;463:25-43.

-38 Ago Y, Koda K, Takuma K, Matsuda T: Pharmacological aspects of the acetylcholinesterase inhibitor galantamine. J Pharmacol Sci 2011;116:6-17. 